\title{
LA IDEA DE FRANCIA EN LA EDUCACIÓN DE LA DICTADURA FRANQUISTA
}

(1939-1960)

\author{
Antonio Gabriel Gisbert Santaballa \\ Departamento de Educación Gobierno de Navarra \\ agsantaballa@gmail.com \\ Juan Madariaga Orbea \\ Universidad Pública de Navarra \\ juan.madariaga@unavarra.es
}

\begin{abstract}
RESUMEN
El tema del artículo es el análisis de la manipulación del discurso histórico en la educación durante los primeros años de la dictadura franquista, y más concretamente en la idea que de Francia y lo francés se transmite al alumnado de Educación Primaria (6-12 años). Por un lado, la concepción de Francia como una potencia enemiga de España, y por otro, la idea de Francia como portadora de la idea de Liberalismo, que el régimen franquista considera peligrosa, y en último término, germen de la II República Española. Se analizarán herramientas de educación formal, en concreto los manuales escolares más utilizados en la época: La Enciclopedia Álvarez y los publicados por la Editorial Bruño.
\end{abstract}

Palabras clave: Libros de texto. Franquismo. Manipulación histórica.

\section{A IDEIA DA FRANÇA NA EDUCAÇÃO DA DITADURA DE FRANCO (1939-1960)}

\section{RESUMO}

O tema do artigo é a análise da manipulação do discurso histórico na educação durante os primeiros anos da ditadura de Franco, e mais especificamente na ideia de que França e o francês são transmitidos para estudantes do ensino fundamental (6-12 anos). Por um lado, a concepção da França como poder inimigo da Espanha e, por outro, a idéia da França como portadora da idéia do liberalismo, que o regime franquista considera perigoso e, em última análise, o germe da Segunda República Espanhola. Esta análise incidirá sobre os livros didáticos do período da ditadura de Franco: A Enciclopédia Álvarez, e os manuais publicados por a Editorial Bruño.

Palavras-chave: Livros didáticos. Franquismo. Manipulação histórica.

\section{THE IDEA OF FRANCE IN THE EDUCATION OF FRANCO'S DICTATORSHIP (1939-1960)}

\begin{abstract}
This essay analyses the manipulation carried by Franco's dictatorship on the historical discourse in Primary Education, focusing on the idea of France that is transmitted to young students (6-12
\end{abstract}


years old). On the one hand, the idea of France as an ancient enemy of Spain, an on the other hand, the idea of France as the vehicle of dangerous ideologies such as Enlightenment and Liberalism, which Franco's Dictatorship relates to those who inspires the Second Spanish Republic. This análisis will focus on textbooks from the Franco's dictatorship period: Álvarez Encyclopedias, and Bruño's publishing house.

Key Words: Textbooks. Franco's Dictatorship. Historical manipulation.

\section{L'IDEE DE LA FRANCE DANS L'EDUCATION DE LA DICTATURE FRANQUISTE (1939-1960)}

\section{RESUME}

Cet essai analyse la manipulation de la dictature franquiste sur le discours historique dans l'enseignement primaire, en se concentrant sur l'idée de la France transmise aux jeunes étudiants (âgés de 6 à 12 ans). D'une part, l'idée de la France comme un ancien ennemi de l'Espagne et, d'autre part, de la France comme véhicule d'idéologies dangereuses telles que le Siècle des Lumières et le Libéralisme, que la dictature franquiste renvoie à ceux qui ont inspiré la Deuxième République espagnole. Cette analyse portera sur les manuels scolaires de la période de dictature franquiste: L'Enciclopedie Álvarez, et les manuels de l'éditorial Bruño.

Mots clés: Manuels scolaires. Dictature Franquiste. Manipulation historique.

\section{INTRODUCCIÓN}

El objetivo de este trabajo es analizar la instrumentalización de la Historia que lleva a cabo la Dictadura franquista, y la ideología que con ella transmite a la población en edad escolar a través de una vía fundamental: los manuales escolares. La reinterpretación de ciertos capítulos de la Historia persigue el adoctrinamiento de los más jóvenes con el objetivo último de crear un nuevo modelo de ciudadano, que apoye el Régimen, a la vez que rechace el sistema republicano anterior.

El franquismo, por lo tanto, utilizará el sistema educativo para legitimar el Golpe de Estado de 1936 y la Dictadura establecida. Esta legitimización va a basarse fundamentalmente en construir un relato de la Historia de España manipulado y modificado, dónde unas épocas y hechos históricos van a ser mitificados, magnificados, engrandecidos, y otros deformados y omitidos. La manipulación a través de la educación formal se va a realizar fundamentalmente a través de los 
manuales escolares, piedra fundamental y casi única de la metodología didáctica de la época, y en los que se observa una clara finalidad manipulativa y persuasiva de control y moldeamiento de la estructura emocional y sentimental de la infancia (MAHAMUD, 2012). El Régimen aplica su currículo y censura a estos materiales, y se encarga de convertirlos en herramientas de transmisión de ideología a través de una enseñanza manipulada de la Historia.

El objetivo de este trabajo es, por lo tanto, analizar los mensajes e ideología que, a través de elementos educativos formales (la Escuela) son transmitidos por la Dictadura a través de una Historia de España manipulada e instrumentalizada.

A este respecto, centraré el objeto de mi investigación en Francia y en los significados que a este país y a lo francés se asocian a través de la escuela a lo largo de la Historia de España. Estos significados y connotaciones serán negativas, ya que el franquismo intentará asociar la idea de Liberalismo a la de "francés", y por lo tanto enemigo extranjero. Se construirá un discurso dónde se pondrá de relevancia una lucha secular entre España y Francia como potencias enemigas. A este binomio francés=enemigo se incorporará el de Ilustración y Liberalismo, y ambos serán explicados como la base de la II República. De este modo, se construye un hilo argumental-histórico que va enhebrando una serie de elementos (Francia, enemigo, extranjero, Ilustración, Liberalismo, antiespañol, II República), con el objetivo último de presentar a la II República como un régimen antiespañol, enemigo y extranjero, y justificar el Golpe de Estado de Julio de 1936.

\section{ESTADO DE LA CUESTIÓN}

Existen varios trabajos que estudian la instrumentalización de la historia por parte de los manuales escolares franquistas. Entre ellos, destacan los de Emilio Castillejo Cabra (2008) y Manuela López Marcos (2001), y estudios más recientes como la obra colectiva coordinada por Francisco José Moreno Martín, El franquismo y la apropiación del pasado (2017).

El trabajo de Emilio Castillejo consiste en analizar los manuales escolares del periodo 1936-1975 como un producto ideológico del franquismo, que además de transmitir conocimientos, transmite una serie de valores.

Castillejo detecta una "univocidad en el discurso ideológico", esto es, una serie de mitos, relacionados con hechos históricos (Reconquista y Reyes Católicos, Descubrimiento de América e Imperio, Guerra de la Independencia), presentes a lo largo de toda la Dictadura en los manuales 
escolares, y cuyo objetivo principal es la legitimación del Golpe de Estado de Julio de 1936, y la existencia de un régimen represivo que utiliza la violencia como forma de control de la sociedad.

Por otro lado, aunque el trabajo de Manuela López Marcos se centra en analizar también la ideología franquista a partir de los manuales escolares, la autora parte de la base de que el franquismo, como régimen e ideología, es un concepto difícil de definir. Esto sería debido a que el corpus ideológico del régimen estaría formado por una serie de elementos heterogéneos, que llevan a los estudiosos a no saber cómo catalogarlo: fascista, autoritario, bonapartista...

López Marcos, por lo tanto, se plantea: ¿Es el franquismo un sistema ideológico coherente y original, o por el contrario reproduce simplemente el discurso de una concepción tradicionalista y anti-liberal de la sociedad, que lucha por la pervivencia de ciertos grupos de poder, y cuyos antecedentes se remontan al siglo XIX?

La conclusión de López Marcos es que el franquismo, más que desarrollar una ideología propia y nueva, reproduce una serie de discursos (nacionalismo, catolicismo, imperialismo, autoritarismo), que ya se observan en manuales escolares de época alfonsina. La última parte de su estudio consiste, pues, en una comparativa de textos y discursos de ambas épocas, lo cual resulta muy revelador a la hora de comprobar la enorme similitud y lugares comunes existentes.

Sobre los estudios más recientes, en la obra que coordina Moreno Martín (2017), se lleva a cabo un análisis de diferentes épocas y conceptos históricos cuyo relato es deformado por el franquismo en libros académicos y manuales escolares, con el fin de legitimar el Régimen y proporcionar una visión providencialista de la Historia. Entre estas épocas y conceptos instrumentalizados, y analizadas en el trabajo, encontramos los íberos y otros pueblos prerromanos, la Hispania Romana, el Reino Visigodo, la Reconquista o los Reyes Católicos.

El análisis concreto del caso de Francia y las ideas que a ella asocia la Dictadura, sin embargo, no se encuentra tan desarrollado como los estudios más amplios y generales sobre franquismo y manuales escolares, y es la voluntad de este trabajo, ahondar en la investigación de estos elementos.

\section{OBJETIVOS}

Los objetivos principales de este trabajo serán, por lo tanto:

- Analizar el discurso manipulado de los manuales escolares del franquismo por el

Rev. Iberoam. Patrim. Histórico-Educativo, Campinas (SP), v. 5, p. 2-21, e019039, 2019. 
cuál se traza una línea clara entre el pensamiento francés de la Ilustración y las Revoluciones Liberales y la Segunda República Española.

Analizar como se utiliza esta asociación por parte de la Dictadura para legitimar el Golpe de Estado de Julio de 1936.

\section{MATERIAL Y MÉTODOS}

Uno de los elementos principales sobre los que se asienta este trabajo son los manuales de texto utilizados durante la dictadura franquista. Más concretamente, se tratan de las Enciclopedias Álvarez de Primero, Segundo y Tercer Grado, y la colección de Historia de España de la editorial Bruño, de Primero, Segundo y Tercer Grado.

En primer lugar se llevará a cabo un análisis del contenido de estos manuales escolares, atendiendo a unas épocas y acontecimientos históricos en concreto: El Despotismo Ilustrado de los primeros Borbones, y la Guerra de Independencia de 1808. Este análisis va a ser fundamental como base de este trabajo, ya que en los textos que recogen encontramos las ideas y valores que, a través de la manipulación e instrumentalización de estos periodos históricos, se identificará al liberalismo como una idea extranjera, y más específicamente francesa, sirviendo a la Dictadura para justificar el Golpe de Estado de Julio de 1936, al interpretar que la II República española es heredera de estas ideas.

Una de las funciones de estos manuales escolares, en lo que se refiere a la idea que de Francia y lo francés se trasmite, va a ser precisamente legitimar el Golpe de Estado y la Dictadura y crear un nuevo modelo de ciudadano afín al Régimen y que asocie la idea de Liberalismo con la de "enemigo extranjero".

Por otro lado, y de forma paralela al análisis del discurso que se establece sobre los primeros Borbones y el Despotismo Ilustrado en los manuales franquistas antes referidos (Enciclopedias Álvarez e Historia de España de la editorial Bruño), se llevará a cabo un estudio comparativo entre este tratamiento y la visión de los manuales escolares republicanos acerca del tema (usando para ello la Enciclopedia Grado Elemental, de la editorial Dalmáu Carles) como método de contraste y comparación, y para desencriptar las ideologías que subyacen en ambas interpretaciones. 


\section{LA INSTRUMENTALIZACIÓN FRANQUISTA DE LA HISTORIA: EL PROVIDENCIALISMO}

Lección $8^{\mathrm{a}}$. España una, grande y libre. El grito de "España, Una, Grande y Libre" expresa de una manera clara y terminante el "como" queremos que España sea. Queremos que España sea UNA, es decir, que todos sus hombres trabajen "unidos" por el bien de la Patria. Queremos que de la unión resulte una España GRANDE, o sea, una España que por su poder sea respetada en el mundo. Y, finalmente, queremos una España que, "unida" y "grande", sea LIBRE, es decir, que no esté sometida a otros países (ÁLVAREZ, 1964: 259)

José María Pemán, uno de los ideólogos más importantes del régimen, escribe en 1938 La historia de España contada con sencillez, para los niños...y para muchos que no lo son. En este libro aparece la expresión "Una, grande y libre” para señalar las tres partes en las que se divide la historia de España. En la primera logra su unidad con los Reyes Católicos, en la segunda (los siglos XVI y XVII) afirma su grandeza y en la tercera (siglos XVIII, XIX y XX) defiende su libertad (PEMÁN, 1938).

La visión de la historia de España defendida por Pemán y por el franquismo es providencialista, y, como señala Luis Mariano González (2009: 162), se puede representar a través de la metáfora de un río, con un principio y un fin inevitable. Esta visión del pasado como un río, la idea del destino, del principio y del final, y de la exaltación franquista del mismo se explica por el profundo carácter religioso del régimen. La visión judeo-cristiana del tiempo y del devenir de la historia enfatiza esta estructura de principio-final, las relaciones de causalidad inevitables, la mano del destino, la providencia, etc. La historia sería para el franquismo, una narrativa, una suerte de cuento donde una serie de hechos históricos se van concatenando de forma infalible, guiados por el destino, hasta llegar a un presente que no puede ser de otra manera ya que los precedentes históricos han llevado de forma irremisible a la situación actual.

En el discurso franquista, el presente español se resume en la máxima "una, grande y libre”. Que la dictadura haya establecido en España un régimen bajo estos postulados, se explica al alumnado, no es por casualidad, sino que es el capítulo final de una larga historia gloriosa a través de la cual se ha forjado la nación española, y donde cada una de estas tres características (una, grande y libre) se han ido alcanzando en etapas históricas bien diferenciadas para construir lo que hoy es un presente completo y glorioso, una meta alcanzada, un mar donde ha desembocado el "río" de la Historia y al que España estaba destinada a llegar de forma inevitable desde el 
principio de los tiempos.

De este modo, y acorde a la división que hace Pemán en 1938, España llega a ser "una" en el reinado de los Reyes Católicos. Una al entender el imaginario franquista que se consiguió la unidad territorial y política de España durante el reinado de los monarcas (cuando en realidad los reinos que formaban la Corona mantuvieron sus propias instituciones, sistemas de peso y medidas, aduanas... hasta los Decretos de Nueva Planta de Felipe V). Pero para los franquistas, casi más importante que la unidad política y territorial, va a ser la religiosa. El Reinado de los Reyes Católicos significa también la expulsión y/o conversión de musulmanes y judíos y la anexión del Reino de Granada. De este modo, el franquismo busca en el pasado de los Reyes Católicos el nacimiento de la nación, pero no solo en términos territoriales, sino también raciales y religiosos. Para el franquismo, ser español, pertenecer a la nación española implica profesar la religión católica, y es por ello que ven en la política religiosa de los reyes católicos, en la expulsión, conversión y establecimiento de la Inquisición, un buen punto de partida para el concepto de unidad de la nación española. El franquismo aúna en su imaginario los conceptos de nación y religión (SOTO, 2012; LOUZAO, 2015). Ser español significa ser católico.

Por otro lado, España es "grande" durante el reinado de los Habsburgo, construyendo un Imperio donde no se ponía el sol. Colonizando América, donde se "evangeliza" a los habitantes, donde se extiende la civilización católica. Intentando "evangelizar" a los protestantes y luchando contra los musulmanes del Mediterráneo. Una época de Imperio donde el nombre de España causaba terror y admiración entre los demás países y a la que el franquismo recurre para elevar la moral de la población, recurriendo a hitos que potencian el orgullo de ser español, en una etapa, 1945-1953, donde España está siendo aislada internacionalmente por las democracias occidentales. La grandeza del Imperio se usa además para legitimar posiciones imperialistas de la dictadura con respecto a África (las negociaciones con la Alemania nazi para entrar en la guerra incluían el Marruecos francés (PARRA, 2012)) y América Latina (imperialismo de tipo ideológico y cultural, transmitiendo la idea de España como la Madre Patria de Iberoamérica (PIQUERAS, 2018)). De este modo, y usando el pasado imperial de la monarquía hispánica, España intenta legitimar sus posiciones imperialistas en el presente.

Una vez unida como nación, y engrandecida por los Austrias a nivel mundial, España sufre para el imaginario franquista una época oscura en la que pierde su hegemonía.

Los ideólogos del régimen achacan esta decadencia a las nuevas ideas racionalistas y

Rev. Iberoam. Patrim. Histórico-Educativo, Campinas (SP), v. 5, p. 2-21, e019039, 2019. 
liberales que, a través del despotismo ilustrado primero, y de la Revolución Francesa después, van a pervertir y debilitar los grandes principios católicos y del Antiguo Régimen sobre los que en su día descansó el Imperio. El culmen de esta decadencia para el franquismo es la invasión francesa de la Península Ibérica por un ejército que blande la bandera de la Revolución Francesa y de sus principios liberales de libertad, igualdad y fraternidad. La gloriosa Guerra de la Independencia contra Francia significa no solo que España recupera su condición de "libre" en el ámbito territorial, sino también en el ideológico y político, al vencer a las ideas liberales con las armas de la religión y la tradición. La victoria en el ámbito territorial implica para el franquismo el concepto del "enemigo exterior", un recurso por el cual el pueblo ofrece su sacrifico y lucha unido, sin disensiones internas, contra el agresor extranjero, sustituyendo la lucha de clases por una lucha entre naciones. Al potenciar esta idea, el franquismo refleja de nuevo la situación de aislamiento internacional (1945-1953) e intenta que la población civil cierre filas en torno a la "nación agredida" y a la dictadura tomando como ejemplo la Guerra de la Independencia.

La lucha en el ámbito político e ideológico es también muy importante para el franquismo y está en estrecha relación con el recurso del "enemigo exterior". Ante todo, la dictadura interpreta la Guerra de la Independencia como una victoria de tipo ideológico de la religión y la tradición, en definitiva del Antiguo Régimen sobre el liberalismo. Al asociar religión-ideología-y nación, como vemos que ya se había hecho a propósito del reinado de los Reyes Católicos (con las expulsiones y conversiones, ser español implica ser católico), el liberalismo queda inmediatamente asociado a elementos "extranjeros", no españoles, en este caso franceses. De este modo, la lucha contra estas ideologías es una lucha contra un enemigo exterior, y los españoles que abrazan las ideas liberales no pueden ser considerados como españoles, sino como traidores a la Patria, enemigos de la nación y colaboradores de potencias extranjeras (QUESADA, 2018). Como ya hemos explicado, el tratamiento de ciertos temas de tipo histórico es utilizado por el franquismo para legitimar y operar posturas políticas en el presente. El "enemigo interior" en el presente de la dictadura estaría formado por el sistema de la Segunda República, la democracia y el movimiento obrero (TÉBAR, 2015). Como herederos directos de las ideas liberales de la Revolución Francesa, la Segunda República es para el franquismo un nuevo ejército invasor, que con sus ideas de progreso y democracia ha intentado destruir las esencias católicas de España. Era por ello necesario un golpe de timón que recondujera la situación y llevara a España de nuevo por el camino, el "río" que le está destinado. El Golpe de Estado y la Dictadura quedan así legitimados. 


\section{LA IDEA DE FRANCIA EN LA EDUCACIÓN FORMAL}

\section{Los primeros Borbones y el Despotismo Ilustrado en los manuales franquistas}

La llegada de la Dinastía de los Borbones en el siglo XVIII a la Corona española inquieta al franquismo por varios motivos. Por un lado, su origen extranjero, más concretamente francés, una potencia con la que se lucha por la hegemonía del continente.

Pero más importante aún si cabe son las ideas y forma de gobierno que la nueva Dinastía trae consigo: El Despotismo Ilustrado. Para el franquismo, la aplicación de políticas ilustradas en España significará una suerte de "invasión" ideológica, de unas ideas extranjeras y violentas con la Religión Católica, que atentan contra un supuesto "espíritu" de la nación española, cuyo origen se pierde en la noche de los tiempos, con supuestos antecedentes históricos como los mártires cristianos de época romana, o la Reconquista, y caracterizado por la tradición y la religión.

El objetivo de la escuela va a ser, por lo tanto, transmitir una imagen distorsionada del Despotismo Ilustrado y de los primeros Borbones, rodeándolos de connotaciones negativas que operen en el alumnado generando rechazo y recelo.

A través de los libros de texto, veremos como el franquismo asocia el liberalismo y la Ilustración con ideas extranjeras, que pertenecen al enemigo que está ocupando y agrediendo España, y que nada tienen que ver con las esencias y sistemas de valores de la nación, de tipo católico y tradicional del Antiguo Régimen. De este modo, los seguidores del liberalismo en España son tachados de traidores a la Patria, de colaboradores con los franceses, y de conspiradores que buscan pervertir el orden social y espiritual de la Nación española. Esta denostación del liberalismo alcanza incluso la etapa del Despotismo Ilustrado español, al cual se presenta como un periodo donde España es atacada desde dentro por sus gobernantes, al aplicar una agenda política inspirada por el racionalismo y la Ilustración francesa, y que va quitando a la religión católica parcelas tradicionales de poder, como la educación. Es significativo como se aborda esta etapa en los manuales escolares: 


\section{FIGURA 1}

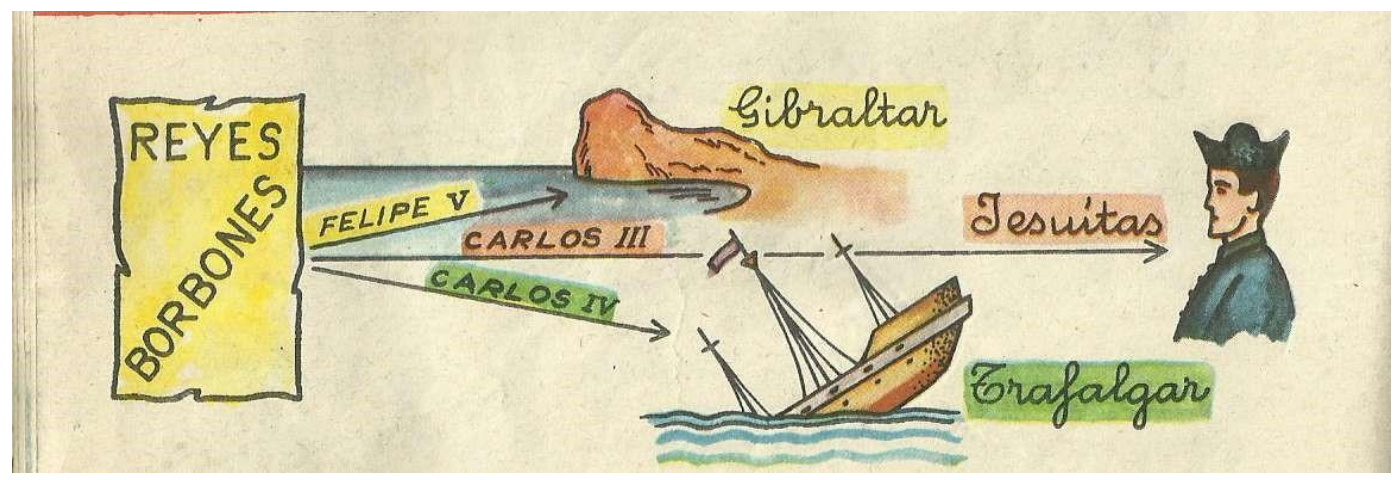

Fonte: ÁLVAREZ, 1964: 214)

La lección 17 de la Enciclopedia de Primer Grado comienza con un dibujo (Figura 1), un diagrama que ya resulta muy significativo y que trasmite una serie de mensajes, directos e indirectos, acerca de la idea que el alumno debe formarse acerca de los monarcas que va a estudiar.

En su forma más evidente, selecciona a tres reyes, Felipe V, Carlos III y Carlos IV, y asocia a cada uno de ellos con un hecho "negativo", un suceso histórico que simboliza la pérdida de poder político, militar, territorial que se han ensalzado en la etapa anterior, la del Imperio. De ese modo, vemos como una serie de flechas unen los nombres de los distintos reyes con estas "derrotas": la pérdida de Gibraltar, la expulsión de los Jesuitas, la derrota naval de Trafalgar. La composición del dibujo cobra fuerza y tiene precisamente un gran impacto visual debido a estas flechas que unen de forma total, en una relación de absoluta causalidad, el reinado de los anteriores monarcas con el concepto de derrota. De este modo, se está transmitiendo al alumno una serie de valores negativos asociados a los reyes Borbones del siglo XVIII, con el claro objetivo de producir en ellos un rechazo hacia sus reinados y decisiones. Un paso más en la graduación que establecerá finalmente la relación entre lo francés y enemigo, y el liberalismo.

A continuación del dibujo, la lectura expone:

Los reyes Borbones eran de origen francés y ocuparon el trono español al morir sin hijos Carlos II, que era uno de los sucesores de Carlos I y Felipe II.

Los principales reyes Borbones fueron: Felipe V, en cuyo reinado perdimos el Peñón de Gibraltar; Carlos III, que cometió el error de expulsar a los Jesuitas, y Carlos IV, en cuyo reinado la escuadra franco-española fue derrotada por la inglesa en la batalla de Trafalgar.

Los reyes Borbones hicieron en España magníficos palacios y bellos jardines, arreglaron las calles y las carreteras y protegieron la cultura, pero el espíritu cristiano de los españoles decayó mucho en su tiempo. (ÁLVAREZ, 1964: 214) 
No solo se acusa de forma explícita al Despotismo Ilustrado y a las ideas de la Ilustración de la pérdida de poder del catolicismo y de un cambio de mentalidad entre ciertos sectores de la población contrarios al Antiguo Régimen, sino que de forma implícita se asocian los hechos más importantes de los monarcas Borbones a derrotas militares, pérdidas territoriales, y medidas anticlericales. (Pérdida de Gibraltar, hito nacionalista e irredentista en el imaginario franquista, derrota de Trafalgar, y expulsión de los jesuitas).

Por otro lado, la idea que transmite el texto es el de los Borbones como un elemento extranjero, una injerencia francesa, que no tiene raíces españolas, y que por lo tanto toma una serie de decisiones equivocadas que llevan a "España” (o al menos la idea de España tradicional, católica que se defiende) a la ruina, precisamente por su condición de extranjeros.

La idea queda así mismo reflejada en la Enciclopedia de Segundo Grado, al leer "Cuando reinaba en España un rey de origen francés, llamado Carlos IV, en Francia lo hacía, al mismo tiempo, un emperador llamado Napoleón” (ÁLVAREZ, 1962, p. 372).

Carlos IV, y todos los significados negativos asociados a su reinado (derrota naval de Trafalgar, debilidad frente a Napoleón), quedan de este modo justificados por su supuesta calidad de extranjero (francés, más concretamente).

Vale la pena reproducir otro fragmento del manual escolar de tercer grado, donde se ahonda en el análisis franquista de lo que significó el Despotismo ilustrado:

Lectura 27

LOS PRIMERO BORBONES Y SU INFLUENCIA EN LA VIDA DEL PUEBLO ESPAÑOL.

Con la venida de los Borbones a España, se produjeron en nuestra Patria (...) transformaciones (...). Por otra parte, de enemigos irreconciliables de Francia nos convertimos en sus amigos, y más tarde, por los torpes Pactos de Familia con ella acordados, en sus aliados y defensores.

No obstante (...) mejoraron mucho a España en el orden material.

Pero todo lo que se ganó en el orden material se perdió en el espiritual, pues el espíritu religioso, clave en los mejores arcos de nuestra historia, fue sustituido por el indiferentismo francés.

Y no es que con ello queramos decir que los monarcas no fueran católicos, pero (...) se dejaron influir por ideas francesas frías con la religión y ello determinó en que se decretara la expulsión de los jesuitas y se tomaran otras medidas poco en consonancia con la tradición cristiana de nuestra nación. A pesar de todo, es digno de hacer notar que la gran masa del pueblo 
español no se contaminó con tales ideas, cuando en la Guerra de la Independencia surgió la ocasión de demostrarlo, (...). (ÁLVAREZ, 1961: 480)

Significativo en este caso el uso del lenguaje. "Nuestra Patria" contrasta con la "venida" de un elemento extranjero, los Borbones, que como vemos provocan una serie de transformaciones negativas en el espíritu mismo del ser español.

Por otro lado, se pone de relevancia la contradicción que supone que España tenga en esta época alianzas con Francia, a la que se tacha de "enemigo irreconciliable", y que con términos negativos como el de "torpe", en relación a los Pactos de Familia, transmite la idea de unos Reyes, débiles, amigos del enemigo, y traidores.

La traición vendría dada fundamentalmente por la pérdida de importancia de lo que el franquismo considera inherente al espíritu de la Nación Española, esto es, la Religión Católica. La ideas francesas y extranjeras de la Ilustración "contaminarían" el espíritu católico español, y la Guerra de la Independencia se presenta como una reacción tradicionalista y "española", una defensa frente a las agresiones intelectuales del Liberalismo.

En conclusión, los manuales escolares presentan a los Borbones llenos de connotaciones negativas asociadas al término francés, como ejemplo a no seguir, y como franceses que acceden al trono español y llevan a cabo políticas nefastas que corrompen y destrozan la grandeza territorial y espiritual del Imperio tradicional español.

\section{EI Despotismo Ilustrado visto por los manuales escolares de la II República}

El franquismo, además, tiene una última razón de peso para encargarse de denostar el periodo de los primeros Borbones y el Despotismo Ilustrado. Y esta es, ni más ni menos, que atacar y desmontar uno de los mitos fundadores del régimen republicano.

Un análisis de manuales de texto de época republicana nos muestra como, para la II República, el Despotismo Ilustrado reúne una serie de valores y significados en los que se quiere encontrar un antecedente histórico "pre-republicano" que legitime el presente y la ideología defendida por el régimen constitucional de 1931.

El análisis del mensaje republicano acerca del Despotismo Ilustrado puede ser muy interesante a la hora de compararlo con el que proyectan los manuales franquistas. Para ello, se 
utilizará el manual escolar de periodo republicano Enciclopedia cíclico-pedagógica de Grado Elemental de la Editorial Dalmau.

Como veremos, la visión que se desprende de los primeros Borbones bajo el prisma del régimen Republicano es radicalmente distinta a la del franquismo. La II República encuentra unos supuestos antecedentes históricos que vienen marcados por la Ilustración Francesa, y sus ideas de Racionalismo frente a la ortodoxia religiosa, Libertad, Progreso, Igualdad (en el sentido de Centralismo), Bienestar del pueblo, Obras Públicas...

Como vemos, los ideales republicanos de Progreso, Cultura, Ciencia, Estado, Racionalismo encuentran uno de sus primeros exponentes en el Despotismo Ilustrado de los Borbones.

Por ello, para los dirigentes republicanos, el primer exponente de todas esas ideas en las que se encuentran las bases fundadoras del republicanismo, son los monarcas Borbones del siglo XVIII.

El manual escolar republicano va a presentar a Felipe V como:

...un monarca ilustrado, amigo del progreso y de la justicia. (...) levantó el espíritu de la nación; protegió la agricultura, la industria, el comercio, las ciencias y las letras, y durante su reinado, España volvió a figurar entre las naciones europeas de primer orden. (DALMÁU, 1938: 248)

Y sobre Carlos III:

Carlos III fue un monarca que solo vivió para el bien de su pueblo: construyó carreteras y canales de riego, levantó grandes edificios públicos en Madrid, fundó las Sociedades Económicas de Amigos del País y trabajó sin descanso por la agricultura, la enseñanza, las ciencias y las artes.

Durante su reinado, España recobró sus antiguas posesiones de La Florida y la isla de Menorca.

Cualidades de Carlos III: Carlos III fue un soberano ilustrado, justo, benéfico, muy virtuoso, atento al bien del pueblo y a los consejos de sus ministros. (DALMÁU, 1938: 248)

Los manuales republicanos, por lo tanto, encumbrarán el Despotismo Ilustrado, y se entiende de este modo mejor la voluntad de la Dictadura por denostar y rodear de connotaciones negativas el pasado de los primeros Borbones. Se trata de destrozar uno de los mitos fundacionales del régimen republicano, y ganar una importante batalla en la guerra de las ideas y de la legitimación histórica. 


\section{La Guerra de la Independencia (1808) como antecedente de la Guerra de Liberación (1936)}

La Guerra de la Independencia representa para el franquismo un dilema ideológico, ya que en ella se encuentran una serie de connotaciones de tipo liberal (la Constitución de Cádiz y el nacimiento del Estado Liberal) que "desvían" a España de su verdadera tradición, en una interpretación de la Historia de España de tipo reaccionario y religioso cuyo máximo exponente es Marcelino Menéndez Pelayo (GARCÍA, 2008: 351).

Por otro lado, la Guerra de la Independencia, como otros elementos históricos, va a ser transformado por el franquismo en un elemento mítico, con la función de legitimar el presente y convertirse en elemento de referencia y antecedente de ese presente en el pasado. Sin embargo, va a resultar un episodio tremendamente complicado a la hora de convertirse en este elemento fundacional o legitimador, precisamente por la heterogeneidad de los grupos políticos que intervienen en el Golpe de Estado de Julio de 1936: tradicionalistas, falangistas, alfonsinos, Acción Católica...

De acuerdo a las tesis de Menéndez Pelayo, que serán finalmente las que se impondrán a otras interpretaciones dentro del Movimiento, en la Guerra de la Independencia se manejan dos conceptos clave.

Por un lado, la interpretación de la lucha contra el francés como una Guerra de Religión contra las ideas de la Ilustración. El tradicionalismo y la religión frente a la razón, el progreso y el liberalismo.

Por otro lado, tras la Guerra, el concepto de "traición" y "derrota". La victoria contra el enemigo francés y sus ideas es aparente, ya que el episodio de las Cortes de Cádiz y el establecimiento del Estado Liberal tras la muerte de Fernando VII es un duro revés a la concepción tradicionalista de la sociedad y de España. El enemigo ideológico contra el que se vierte sangre y sufrimiento, acaba finalmente gobernando el país por la traición de unos malos españoles, los liberales. En palabras de Menéndez Pelayo:

... gracias a aquellas reformas [la Constitución de 1812] quedó España dividida en dos bandos, iracundo e irreconciliables; llegó, en alas de la imprenta libre (...), la voz de sedición contra el orden sobrenatural, lanzada por los enciclopedistas franceses (...), perdido en la lucha el prestigio del trono, socavado en mil maneras el orden religioso, constituidas y fundadas las agrupaciones políticas (...), comenzó esa interminable tela de acciones y de reacciones, de anarquías y de dictaduras, que llena la torpe y miserable historia de España en el siglo XIX. (MENÉNDEZ PELAYO, 1934: 235) 
Pese a las connotaciones liberales del hecho histórico y los peligros de su interpretación, Rafael Cruz Martínez (2008: 333) ya identifica con anterioridad al 18 de Julio de 1936, entre la derecha antirrepublicana, una transposición del momento político presente, al supuesto antecedente histórico de la Guerra de la Independencia, y cita que con motivo de las elecciones de Febrero de 1936, ABC plantea que se enfrentan dos banderas:

Una representa la vida de España como nación, su continuidad histórica, su bienestar, su paz, su progreso. Otra, el sometimiento a la dictadura de los dictadores del proletariado, la miseria y la esclavitud para todos, la desaparición de España libre y digna en manos de poderes extranjeros (...) defender a España con el voto como se la defendería con un fusil. Ésta también es una guerra de la independencia". (CRUZ, 2008: 333)

Los elementos de asociar República a algo extranjero, y buscar un antecedente histórico en la Guerra de la Independencia para legitimar un golpe armado contra el sistema republicano, queda en este fragmento patente.

Ya en los primeros días de la Guerra, encontramos las primeras referencias a la Guerra de la Independencia como herramienta de propaganda y arenga, centrándose el discurso, como no podía ser de otra manera, en el carácter extranjero del enemigo al que se combate. José María Pemán, el 24 de Julio de 1936, a través de las ondas de Radio Jerez (controlada por Queipo de Llano), arengaba de este modo: “...guerra santa en que el Ejército y el pueblo, puesto unánimemente de pie, vuelven a gritar a todos los vientos que si ayer la Virgen del Pilar no quería ser francesa, menos quiere ser ahora rusa ni judía...” (PEMÁN, 1937: 12)

El recurso al enemigo extranjero no sirve solo para legitimar el Golpe de Estado, cerrar filas en torno a una supuesta amenaza extranjera, y convertir la lucha de clases en una lucha entre naciones, sino que, como señala Hugo García (2008: 361), "la desnacionalización del enemigo (ajeno a la esencia de lo español, defensor de ideas extranjeras, apoyado por potencias enemigas), [es] condición necesaria para su deshumanización".

La Guerra de la Independencia tiene para el franquismo, como vemos, un enorme potencial como símbolo de carácter instrumental para legitimar, en sucesos del pasado, el Golpe de Estado de 1936. Dando énfasis al mito del 2 de Mayo, se traslada el mensaje de que España tiene una tradición de "rebeldía" e "insumisión" frente a poderes extranjeros que intentan someterla. En este sentido, Hugo García (2008: 361), explica que la Guerra de la Independencia tiene un 
encaje mucho más fácil en las circunstancias presentes de la Guerra Civil, que de lo que puedan tener otros mitos fundacionales similares como el de la Reconquista (con un gran peso del elemento religioso y de Cruzada, pero contra un enemigo, el musulmán, que en el caso de la Guerra Civil es aliado y ayuda a los sublevados).

Con lo visto anteriormente, el objetivo principal del franquismo respecto a la enseñanza en las escuelas y en relación a la Guerra de la Independencia, es establecer una línea argumental ideológico-histórica entre los años 1808 y 1936, con los denominadores comunes de existencia de un espíritu o esencia española ineludiblemente unida a la religión católica y a la tradición; un agresor extranjero, una potencia enemiga, (Francia en la Guerra de la Independencia), que intenta conquistar y destruir España no solo a través de los ejércitos sino de las ideas (el Liberalismo); una "traición" tras la Guerra de la Independencia, el establecimiento de un sistema "extranjero" y "enemigo", y encontrar el máximo exponente del mismo, y por lo tanto de la ruina de España, en la II República Española. Todo ello con el objetivo de legitimar el Golpe de Estado de 1936 y el establecimiento de la Dictadura franquista.

Es curioso el paralelismo que existe en el discurso con el que se interpretan ambos momentos históricos:

Sobre la Guerra de la Independencia:

Hace muchos años un emperador francés llamado Napoleón quiso apoderarse de España (...). Los españoles se levantaron contra él con mucha valentía (...) y los echaron otra vez para Francia. Esta gloriosa guerra se llama Guerra de la Independencia" (ÁLVAREZ, 1965: 92)

Sobre el Alzamiento Nacional:

Hace varios años España estaba muy mal gobernada (...). Para acabar con todo esto, Franco se sublevó con el ejército y (...) logró echar de nuestra Patria a sus enemigos (...)" (ÁLVAREZ, 1965: 108).

En ambos, el denominador común es el de Guerra contra un enemigo al que no se considera español, al que se define como ajeno a la Patria. En ambos casos el resultado final es la victoria mediante la expulsión del enemigo. Las ideas que operan en el estudiante al presentarse un acontecimiento sucediendo al otro, en lo similar de la estructura de los discursos, y en que el resultado final sea la expulsión del enemigo de la Patria, es que tanto franceses como republicanos 
no pertenecen a la Patria. Son elementos extranjeros (no solo ellos, sino también sus ideas), y por lo tanto, enemigos que quieren perjudicar a España y que deben ser combatidos. El Golpe de Estado de 1936 queda de este modo legitimado ante los estudiantes de "el Parvulito", al entender que era necesario para librar al país de un elemento peligroso y extranjero que lo estaba perjudicando, y que encuentra su antecedente histórico más inmediato y potente en una Guerra de la Independencia contra el invasor francés.

Comienza a trazarse pues desde edades muy tempranas la línea ideológica que pretende identificar las ideas de Liberalismo con las de "extranjero" y "enemigo" de España, asociándolas a Francia.

En el siguiente nivel, la Enciclopedia de Primer Grado insiste en la idea de asociar ambos procesos, Guerra de Independencia y Alzamiento Nacional, siguiendo el esquema ideológico de lucha contra el enemigo "exterior" e "interior". Tras una lección 18 centrada en la Guerra de la Independencia donde "los españoles se levantaron contra el invasor francés (...) y tuvieron que regresar a Francia sin conseguir sus objetivos" (ÁLVAREZ, 1964, p. 216), encontramos:

\section{LECCIÓN 19}

\section{LA GUERRA DE LIBERACIÓN}

Después de la Independencia, otra vez volvió España a estar mal gobernada. La religión era perseguida, los asesinatos y las huelgas eran diarias y nuestra Patria estaba a punto de caer en manos del comunismo.

Para acabar con tantos males, Franco inició (...) la guerra de Liberación Nacional (...) para librar a España de sus enemigos y hacerla Una, Grande y Libre. (ÁLVAREZ, 1964: 217)

De nuevo, el paralelismo entre ambos procesos. El elemento extranjero, antiespañol, peligroso y nocivo que debe ser expulsado.

Pero el elemento clave a la hora de entender la interpretación del periodo y el mensaje que se quiere transmitir, es la idea de "traición", que ideólogos del Régimen como Pemán defienden a la hora de explicar el establecimiento del Estado Liberal tras la Guerra de la Independencia (GARCÍA, 2008: 370). Encontramos su reflejo en manuales escolares:

En la Guerra de la Independencia había triunfado plenamente el pueblo español, pero las clases directoras se habían dejado influir por ideas de origen francés. Y así se dio el caso de que mientras unos españoles morían en los campos de batalla defendiendo a su Dios, a su Patria y a su Rey, otros formaban en Cádiz unas Cortes al estilo francés y aprobaban un reglamento llamado Constitución (...) 
cuando Fernando VII regresó, encontró a los españoles divididos en dos bandos: los llamados absolutistas, defensores de la tradición española sintetizada en las palabras Dios, Patria y Rey, y los llamados liberales, que defendían la constitución y que estaban contaminados con ideas de origen francés.

Al morir Fernando VII estalló la primera guerra carlista (...). El triunfo fue para los liberales, y con él, aumentó el malestar y la decadencia de España. (ÁLVAREZ, 1962: 377).

En este sentido, el carlismo se presenta como una reacción genuinamente española y tradicionalista contra el Liberalismo, ideología enemiga, de origen extranjero, que atenta contra la religión, y que se identifica como la causa principal de un siglo XIX al que se retrata como inestable y decadente. De este modo, encontramos en textos escolares, a propósito de la Primera Guerra carlista.

LECCIÓN 23. España en el siglo XIX. Durante el siglo XIX la vida española se vio perturbada por infinidad de revueltas y luchas civiles entre absolutistas y liberales. Las doctrinas liberales eran de origen extranjero y ocasionaron muchos males a España. (ÁLVAREZ, 1962: 378).

Los carlistas defendían las ideas tradicionales (...), mientras que los liberales defendían las ideas de origen extranjero. (ÁLVAREZ, 1961: 486).

Una nueva asociación de las ideas liberales con el enemigo francés, y por lo tanto, con un elemento anti-español, nocivo, y que agrede el "espíritu" de España, llevándola a la decadencia.

\section{CONCLUSIONES}

A través del presente trabajo, hemos analizado como, del mismo modo que una serie de etapas de la Historia de España son glorificadas por el régimen, otras muchas van a ser ignoradas y denostadas. El Despotismo Ilustrado, asociado a Francia, se va a contar entre ellas, ya que para el imaginario del régimen es en esta época cuando se introducen las primeras ideas liberales nocivas para España por parte de los gobernantes, que van a conspirar desde dentro para socavar las ideas católicas y del Antiguo Régimen.

La Guerra de la Independencia, significaría, siguiendo esta línea de pensamiento, una reacción frente al enemigo interior del liberalismo (que a su vez se identifica como extranjero, ideas venidas de Francia y que han contaminado a unos traidores internos), en donde España recupera sus esencias más tradicionalistas y religiosas, aquellas que en el imaginario del régimen la hicieron 
grande durante el Imperio

El tema del enemigo exterior es tratado por los manuales escolares de la dictadura como reflejo de la situación presente y con el objetivo de legitimar el golpe de Estado de 1936, la Guerra Civil y el régimen fascista. El sistema instaurado por la Segunda República va a ser considerado por la derecha española como heredero de los valores revolucionarios y democráticos de la Revolución Francesa, y por lo tanto, acusado de pervertir las esencias católicas y tradicionales de España en su intento de modernizar el país y apartar la religión de la vida pública. La lucha contra la Segunda República y sus partidarios toma el cariz de una segunda Guerra de la Independencia (Guerra de Liberación de 1936, como rezan los manuales escolares) donde de nuevo el glorioso pueblo español se levanta en armas contra el enemigo extranjero (el comunismo) y sus aliados internos, traidores, afrancesados, que por su ideología no pueden ser considerados en ningún caso como españoles.

De este modo, el franquismo intenta a través de la instrumentalización del discurso histórico, justificar el golpe de Estado, la Guerra Civil, las depuraciones, y el establecimiento de la Dictadura. Manipulación del discurso histórico que encuentra en los manuales escolares más utilizados durante las décadas de los 40, 50 y 60 (Enciclopedia Álvarez e Historia de España de Bruño) un medio eficaz para crear un nuevo modelo de ciudadano, afecto al Régimen, y que rechace el sistema de valores republicanos anterior a 1939.

\section{REFERENCIAS}

ÁLVAREZ BARRIENTOS, Joaquín. (ed.). La Guerra de la Independencia en la cultura española. Madrid, Siglo XXI, 2008, 400.

ÁLVAREZ PÉREZ, Antonio. Eı Parvulito, Valladolid, Miñón, 1965.

ÁlVAREZ PÉREZ, Antonio. Enciclopedia Primer Grado, Valladolid, Miñón, 1964.

ÁLVAREZ PÉREZ, Antonio. Enciclopedia Segundo Grado, Valladolid, Miñón, 1962.

ÁlVAREZ PÉREZ, Antonio. Enciclopedia Tercer Grado, Valladolid, Miñón, 1961.

CASTILLEJO CAMBRA, Emilio. Mito, legitimación y violencia simbólica en los manuales escolares de historia del franquismo. Madrid, UNED, 2008.

CRUZ MARTÍNEZ, Rafael. Guerra hasta la última tapia. La historia se repite ciento treinta años

Rev. Iberoam. Patrim. Histórico-Educativo, Campinas (SP), v. 5, p. 2-21, e019039, 2019. 
después. En ÁLVAREZ BARRIENTOS, Joaquín. (ed.) La Guerra de la Independencia en la cultura española. Madrid, siglo XXI, 2008.

GARCÍA, Hugo. (2008). ¿El triunfo del Dos de Mayo? La relectura antiliberal del mito bajo el franquismo. En ÁLVAREZ BARRIENTOS, Joaquín. (ed.) La Guerra de la Independencia en la cultura española. Madrid, siglo XXI, 2008.

IBÁÑEZ MARTÍN, José. Hacia un nuevo orden universitario. Valladolid, 1940.

LÓPEZ MARCOS, Manuela. El Fenómeno ideológico del franquismo en los manuales escolares de enseñanza primaria (1936-1945). Madrid, UNED, 2001.

LOUZAO, Joseba. La restauración social católica en el primer franquismo, 1939-1953, Universidad de Alcalá, Servicio de Publicaciones, 2015.

MAHAMUD ANGULO, Kira. Adoctrinamiento emocional y socialización política en el primer Franquismo (1939-1959): emociones y sentimientos en los manuales escolares de enseñanza primaria. 2012 Tesis Doctoral - UNED.

MENÉNDEZ Y PELAYO, Marcelino. Historia de España, Madrid, Sociedad Cultura Española, 1934.

MORENO MARTÍN, Francisco José (coord.). El franquismo y la apropiación del pasado: el uso de la historia, de la arqueología y de la historia del arte para la legitimación de la dictadura. Madrid, Editorial Pablo Iglesias, 2017, 335.

PARRA, D. La narrativa del africanismo franquista: génesis y prácticas socio-educativas. 2012. 410 páginas. Tesis (Doctorado en Nuevas Perspectivas en Historia Contemporánea) Universidad de Valencia.

PEMÁN, José María. Arengas y crónicas de guerra, Cádiz, Cerón, 1937.

PEMÁN, José María. La historia de España contada con sencillez, Cádiz, Cerón, 1938

PIQUERAS, J.A. "Operación Hispanidad": políticas del pasado y verdad española en el primer franquismo. En JORGE, D. (coord). Tan Lejos, tan Cerca: Miradas Contemporáneas Entre España y América Latina. Tirant Lo Blanch Ediciones, 2018, 498.

PRESTON, Paul. La política de la venganza. EI fascismo y el militarismo en la España del siglo XX. Barcelona, Península, 1997.

QUESADA, Zulema. La percepción de Europa en los manuales escolares de Historia en la España franquista (1939-1975): entre la indiferencia y la superioridad. RUE: Revista universitaria europea, n. 29, p. 23-53, Julio-Diciembre 2018. 
SOTO, D. "Para con Dios y la Patria": representación y autoridad en el caudillismo franquista.

Confluenze: Rivista di Studi Iberoamericani, Università di Bologna, Vol. 4, N. 2, 2012.

TÉBAR, Ignacio. La representación del enemigo en el Derecho penal del primer franquismo (1938-1944). 2015. Tesis (Doctorado en Sociedad y Estado en España. Siglo XIV-XX) Universidad de Alicante.

VV.AA. Enciclopedia Grado Elemental, Gerona, Dalmáu Carles, 1938.

VV.AA. Historia de España. Primer Grado, Madrid, Bruño, 1946.

VV.AA. Historia de España. Tercer Grado, Madrid, Bruño, 1949.

Recebido em: 17 de dezembro de 2018

Aceito em: 23 de dezembro de 2019 